\title{
"É A MACROECONOMIA, IDIOTA!"
}

\author{
Lena Lavinas \\ Universidade Federal do Rio de Janeiro, Rio de Janeiro, Brasil
}

\begin{abstract}
Resumo: Esse artigo debate alguns pontos desenvolvidos no mais recente relatório das Nações Unidas intitulado Avanços do Mundo das Mulheres 2015-2016 - Transformando as Economias, Implementando Direitos, que trata da persistência das desigualdades de gênero no mundo contemporâneo. Explora notadamente aspectos ligados às consequências das políticas macroeconômicas ortodoxas na reprodução dessas desigualdades por restringir o gasto público e as políticas universais.
\end{abstract}

Palavras-chave: ONU Mulheres; gênero e macroeconomia; gênero e políticas heterodoxas.

A cada ano aprimora-se o savoir faire das Nações Unidas na preparação e difusão de relatórios sintéticos recheados de ilustrações empíricas e belíssimos esquemas elucidativos. E, ademais, solidamente apoiado em estatísticas nacionais, reunindo na sua elaboração equipes transnacionais, altamente qualificadas, com expressivo e incontroverso background acadêmico.

Dessa vez não foi diferente. Um documento de quase 350 páginas, intitulado Avanços do Mundo das Mulheres 2015-2016 - Transformando as Economias, Implementando Direitos (tradução nossa), traz um apanhado vasto e diverso de questões que dizem respeito a uma trajetória que se mostra, a despeito de progressos notáveis no passado recente, estancada, senão interrompida. É como se o devir das mulheres de alguma forma seguisse rota semelhante à daquele mundo mais igualitário, do bem-estar compartilhado do pós-guerra, fruto de um capitalismo regulado com forte intervenção do Estado. Tudo parece em risco. $O$ progresso não é linear e os valores seculares de igualdade, fraternidade e liberdade da modernidade podem vir a sofrer revezes. Isto é, depois da maior revolução do século XX, revolução essa sem caminho de volta por ter questionado em definitivo - e no âmago das nossas consciências - a ordem patriarcal, redefinindo as relações de hierarquia e de subordinação entre os sexos, o quadro é de relativa letargia. Obstáculos velados, ainda que conhecidos, desafiam Constituições que, em 143 países, num total de 201 (UN WOMEN, 2015 , p. 29), introduziram na sua carta magna o princípio da igualdade entre homens e mulheres.

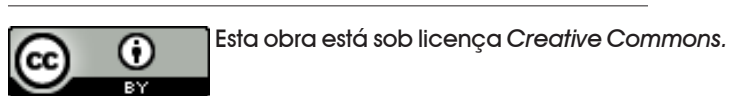


A conclusão é de apreensão tão fácil quanto esperada: a igualdade formal não resultou em uma igualdade substantiva. Se aquela "refere-se à adoção de leis e políticas que tratam igualmente homens e mulheres, a igualdade substantiva diz respeito aos efeitos e ganhos dali derivados" (UN WOMEN, 2015, p. 12). Igualdade substantiva é tão somente igualdade real, efetiva, genuína. Aquela que aos nossos olhos funciona de fato.

O bom dessa prática de balanço e disseminação é monitorar, com relativa frequência, a quantas anda o respeito à ICESCR ou Convenção Internacional dos Direitos Econômicos, Sociais e Culturais, e a CEDAW - Convenção pela Eliminação de Todas as Formas de Discriminação Contra as Mulheres, ambas já velhas de algumas décadas ${ }^{1}$.

O ponto de partida do informe é refletir sobre uma realidade amplamente denunciada e objeto de incontáveis trabalhos de feministas mundo afora: a participação feminina na força de trabalho estacionou, como se restringida por um teto; o hiato salarial entre homens e mulheres mantém-se quase inalterado, com elas ganhando, numa média global, cerca de $24 \%$ a menos, tendência de convergência essa negativa, uma vez que se deu a partir da queda dos rendimentos masculinos e não da maior elevação dos femininos; em todas as regiões do mundo, elas seguem trabalhando muito mais horas que os homens, isso porque ocupações não remuneradas na economia dos serviços e o trabalho doméstico continuam sendo exercidas por mulheres e são, por isso mesmo, desvalorizadas; a cobertura previdenciária feminina ainda está muito aquém do necessário, já que elas que são maioria entre os $3 / 4$ da população mundial sem nenhuma proteção social ou com acesso parcial e deficiente; a baixa provisão dos serviços públicos pressiona o trabalho não remunerado das mulheres.

A lista, evidentemente, é bem mais extensa, mas só pelos pontos citados mereceria compêndios que contribuíssem para fazer valer os direitos humanos também para mulheres e meninas. Göran Therborn, no seu magistral livro The Killing Fields of Inequality (2013), afirma, apoiado em numerosas e incontestáveis evidências, que a desigualdade mata. Disso sabemos bem nós, mulheres, quando nos é negado o direito ao aborto legal e seguro ou quando somos as vítimas imediatas da negligência das políticas de saúde em matéria de direitos reprodutivos, que não poupam tampouco aos nossos filhos. Ou ainda por convivermos de forma mais assídua com a pobreza extrema, que inviabiliza o futuro. Para Therborn, que toma emprestada de Amartya Sen, para aprimorá-la, a definição de desigualdade, esta se consubstanciaria em "violações dos direitos humanos que comprometem o pleno desenvolvimento humano dos indivíduos" (Göran THERBORN, 2013, p. 41). Sim, é disso que se trata. A desigualdade de gênero nos seus diversos matizes e expressões é uma violação reiterada do nosso potencial de realização como ser humano. Esse devir furtado acaba por fazer crer aos míopes, insignificantes ou de má fé que seríamos incompletas, inacabadas, quando é a negação reiterada da nossa plenitude como seres humanos que subtrai nosso engrandecimento.

\section{Um enfoque crítico e contrário à primazia neoliberal da solução das falhas de mercado}

Para além de retomar temas recorrentes no debate feminista e atualizar um amplo conjunto de indicadores das assimetrias entre homens e mulheres, o relatório chama atenção por apoiar-se numa interpretação pouco frequente, por parte dos órgãos multilaterais, do papel da política macroeconômica na garantia dos direitos sociais e das mulheres, em particular.

'A ICESCR data de 1966, entrando em vigor a partir de 1976, ao passo que a CEDAW foi instituída em 1979. 
Depois de assinalar que emprego remunerado é indispensável, porém insuficiente para oferecer uma vida digna, longe da pobreza, o documento aponta ser incontornável expandir a proteção social e a provisão pública de serviços sociais com o intuito de superar as disparidades de gênero. A novidade aqui reside em reconhecer que:

1) As políticas focalizadas, que se serviram do falso argumento de empoderamento das mulheres na condição de beneficiárias das transferências de renda, podem até atenuar déficits monetários, mas mostram-se incapazes de reverter de forma duradoura as desigualdades de gênero (UN WOMEN, 2015, p. 135). Elas tendem a excluir os mais vulneráveis, negando-lhes cobertura e, por isso mesmo, são nocivas às mulheres, sem contar seu efeito colateral no reforço a estigmas persistentes (UN WOMEN, 2015, p. 140). Finalmente, o relatório admite que as condicionalidades que acompanham os programas de transferência de renda focalizados nos comprovadamente pobres representam custos de inconveniência elevados para as mulheres, penalizando-as, bem como aumentam os custos administrativos, gerando ineficiências.

2) A alternativa que se coloca, portanto, está em transitar para sistemas de cobertura universal, que se revelam, de fato, gender-responsive, ou sensíveis ao gênero (isto é, são capazes de automática e imediatamente atenuar tais diferenciais, em favor das mulheres).

Exemplos não faltam para justificar a defesa das políticas universais, vilipendiadas que foram nas últimas duas décadas em nome da austeridade fiscal e de pretensos ganhos de eficiência. Dessa maneira, o corte de gastos e a opção pela privatização eram enganosamente legitimados em nome da priorização dos pobres (Lena LAVINAS, 2013b). llustram tais alternativas consequentes as aposentadorias universais, como a Renda Dignidad na Bolívia ou a Aposentadoria Básica da llha Maurício, que, além de universais, são incondicionais, à imagem das aposentadorias rurais no Brasil; portanto, dispensam contribuição prévia. Não por acaso, em todos os casos citados, a maioria dos beneficiários são mulheres. E lá onde foi estendido o tempo de contribuição - na Argentina (UN WOMEN, 2015 , p. 153) -, ou mantidas as contas individuais para aposentadorias - no Chile (UN WOMEN, 2015, p. 150) -, o hiato de renda entre homens e mulheres não cedeu, muito pelo contrário.

O relatório claramente se coloca a favor dos sistemas de repartição contributivos (PAYG) ou universais que, como já foi documentado por grande número de estudiosos do seguro social (Nicholas BARR, 2004), é a única maneira efetiva de equalizar benefícios previdenciários. É sabido que o sistema de repartição reduz as desigualdades de renda entre os aposentados de ambos os sexos, pois compensa a baixa capacidade contributiva das mulheres. Os sistemas de capitalização, baseados em contas individuais, ao contrário, não permitem redistribuição através de um pool que mitigue riscos. Ora, como as mulheres têm uma inserção ocupacional bem mais precária e informal, com frequentes entradas e saídas no mercado de trabalho, elas forçosamente são prejudicadas pelo sistema de capitalização, dificilmente preenchendo os requisitos para alcance de um benefício que, ao fim e ao cabo, será sempre inferior ao dos homens em razão da maior longevidade feminina. Ou seja, nos sistemas de capitalização, as poucas vantagens das mulheres resultam em prejuízo.

No caso das políticas de combate à pobreza através dos $\mathrm{CCTs}^{2}$, a Bolsa de Apoio às Crianças da África do Sul ${ }^{3}$ é exemplo de benefício livre de condicionalidades, ao lado de todas as alocações a famílias com crianças, vigentes na ampla maioria dos países da União Europeia (estas, universais, além de incondicionais), no intento de prevenir a destituição.

${ }^{2}$ Conditional Cash Transfers, tal como referendado na bibliografia internacional.

${ }^{3}$ South African Child Support Grant. 
Da mesma maneira, somente políticas universais vão reparar e compensar o trabalho doméstico não remunerado e a economia do care, hoje atribuições femininas. Com elas, as mulheres são alcançadas por mecanismos de proteção social independentemente da sua trajetória e do seu status profissional. O exemplo aqui consiste nos créditos de cuidados, que funcionam em particular nos países desenvolvidos, embora estejam gradualmente sendo implementados em alguns países latino-americanos, como Uruguai e Bolívia (UN WOMEN, 2015, p. 153). Essa modalidade de compensação destina-se a preencher a ausência de contribuições nos períodos em que as mulheres tiveram de ausentar-se do mercado de trabalho para cuidar dos filhos menores ou de outro dependente com a finalidade de garantir tempo de contribuição ao seguro social. Revela o relatório que, embora presente em muitos países da OCDE (Organização de Cooperação e Desenvolvimento Econômico) os créditos de cuidados só funcionam bem onde são generosos e também estendidos aos homens, para romper com estereótipos da divisão sexual e social do trabalho. E isso ocorre nos países nórdicos, une fois n'est pas coutûme!

\section{A provisão pública como mecanismo de equalização e a macroeconomia necessária}

Outro resgate do documento trata da centralidade do investimento em serviços sociais e na garantia de uma provisão pública na quantidade e na qualidade esperadas para reverter níveis agudos de desigualdade e de destituição. Políticas universais, reconhece o estudo, são gender-responsive se talhadas de modo a considerarem as iniquidades entre os sexos, o que não acontece com políticas residuais.

O relatório é enfático ao sublinhar o alerta já feito por muitos autores, inclusive nacionais (Lena LAVINAS, 2007; 2013a): há que priorizar o gasto in kind, com provisão desmercantilizada de serviços, considerando as evidências irrefutáveis de que seu impacto na redução da pobreza e da desigualdade ultrapassa em muito o das transferências monetárias (UN WOMEN, 2015, p. 156). Estas tendem a resolver falhas de mercado, incentivando a privatização dos serviços nos setores onde a provisão pública é falha (LAVINAS, 2013b).

No caso das assimetrias de gênero, a coisa funciona mais ou menos assim: os homens dependem das mulheres para dispor de bem-estar e qualidade de vida, enquanto as mulheres precisam de serviços públicos acessíveis e a custos razoáveis para não serem as únicas provedoras responsáveis por assegurar, para além de suas capacidades, recursos e vontade, condições satisfatórias de reprodução da vida. Na ausência da provisão pública adequada, a carga repousa quase que exclusivamente sobre as mulheres, sobre o trabalho não remunerado e invisibilizado das mulheres.

Ora, dada a compreensão e o alcance de um problema familiar e premente para as mulheres no seu cotidiano, surpreende a afirmação, à página 132 do documento, de que o pensamento feminista não enfrentou a controvérsia bens públicos versus transferências monetárias e que só agora isto estaria posto. Essa afirmação não procede. Maxime Molineux (2006), Sylvia Chant (2007), Lena Lavinas, Barbara Cobo e Aline Veiga (2012), Barbara Cobo (2012), Rubén Lo Vuolo $(2015 ; 2013)$ são alguns dos estudiosos dos sistemas de proteção social, da pobreza e/ou das iniquidades de gênero que denunciaram a opção pelas condicionalidades e transferências monetárias em detrimento da provisão universal e incondicional.

A chave de leitura e, ao mesmo tempo, o diferencial do documento é indubitavelmente o de traduzir, de forma didática e empiricamente apoiada, por que política econômica e política social devem andar juntas, integradas, numa complementariedade positiva. Logo, 
ressalta que a separação entre política econômica e política social é artificial e não procede (UN WOMEN, 2015, p. 209).

Mais uma vez a didática do relatório garante o amplo entendimento dessa relação muitas vezes omitida. Com grande simplicidade e clarividência, o capítulo 4 " Favorecendo um ambiente macroeconômico transformador - discorre sobre os segredos da macroeconomia e esclarece as distintas formas de se financiarem políticas sociais. Indica os componentes da política macroeconômica e, sobretudo, demonstra como elevação de juros (política monetária) e, em certos casos, moeda sobrevalorizada (política cambial) podem ser extremamente prejudiciais ao bem-estar das mulheres por reduzirem suas oportunidades de emprego, agravando a informalidade e o grau de sua cobertura protetiva.

O mote desse capítulo é explicitar quão falso é o pressuposto de que a política macroeconômica e a política fiscal são neutras vis-à-vis o gênero, ambas carregando, portanto, vieses que podem agravar as desigualdades entre os sexos (UN WOMEN, 2015, p. 207). Recorda que incentivos tributários via mercado de trabalho formal tendem a favorecer grandemente os homens, dado a inserção diferenciada de trabalhadores e trabalhadoras no mercado de trabalho. Os impostos indiretos fortemente regressivos, por exemplo, afetam a todos, porém, sobremaneira, as famílias chefiadas por mulheres cujo número, numa média internacional aproximada, avizinha $15 \%$. Sua renda disponível, já baixa, cai ainda mais, tornando a pobreza uma ameaça à espreita. O documento explica por que financiar políticas sociais a partir do endividamento do Estado pode ser uma opção de alto risco, considerando a volatilidade da taxa de câmbio. Detalha o papel regulatório dos bancos centrais, notadamente na gestão da taxa de juros e na oferta de crédito, e como uma e outra repercutem no emprego e no bem-estar das mulheres.

Esse capítulo reproduz a estrutura adotada nos capítulos anteriores. Inicia com a identificação dos desafios inerentes ao tópico tratado; na sequência, expõe as alternativas existentes no campo das políticas públicas para enfrentar tais desafios; por fim, inclui uma síntese e as recomendações, todas elas considerando as dimensões analisadas das políticas macroeconômicas. Entretanto, aporta um plus considerável: afirma que a igualdade substantiva não pode prescindir de uma redefinição da políica macroeconômica que hoje orienta a tomada de decisão num mundo globalizado, crescentemente conduzido pelo capitalismo financeiro e desregulado. Ou seja, o documento posiciona-se claramente no entendimento de que "políticas macroeconômicas podem limitar ou ampliar as possibilidades de reverter as desvantagens socioeconômicas das mulheres" (UN WOMEN, 2015, p. 194, tradução nossa), dependendo de seu desenho e metas.

Trata-se, portanto, de um posicionamento manifesto em favor de políticas fiscais expansivas, preferencialmente voltadas para o investimento em saúde, creches, educação, infraestrutura urbana, cuidados, em lugar do subsídio ao consumo, padrão este que prevaleceu, inclusive, no Brasil dos anos 2000 (Lena LAVINAS, 2015). Alerta que a política monetária não pode ter como meta exclusiva o controle da inflação, sob pena de comprometer o emprego, fonte maior de bem-estar de todos, e, com ele, as receitas essenciais ao aumento da redistribuição. E acrescenta que ela deve funcionar para promover os direitos humanos! (UN WOMEN, 2015, p. 215).

Nada mais distante da realidade de hoje, numa Europa massacrada pelas políticas de austeridade, com hordas de jovens desempregados, cortes nos benefícios sociais e aumento das desigualdades de todo tipo. E também numa América Latina onde predominaram as políticas pró-cíclicas de cunho neoliberal, lideradas por coligações ditas de centro-esquerda, populares, preocupadas tão somente em forjar a transição para uma sociedade de consumo de massa, sem superação das nossas heterogeneidades estruturais. 
O tom e o eixo do documento agradam, notadamente neste capítulo 4, porque alinham os interesses das mulheres ao campo progressista, heterodoxo, se assim se pode denominá-lo. Resta saber como se pensa recompor o campo de forças para que o potencial de luta das mulheres garanta que o pêndulo das políticas macroeconômicas se mova na direção certa, arrastando reformas tributárias que sejam redistributivas e equalizadoras de oportunidades entre homens e mulheres.

É, portanto, o documento uma boa carta de princípios que situa a luta das mulheres por igualdade num contexto de superação do pensamento conservador que hoje define e configura políticas econômicas e sociais mundo afora. Apesar de inconsistências ao citar - Brasil como exemplo de boas práticas ${ }^{4}$, resgata o campo de batalhas onde devemos atuar. E nele, o lado no qual nos situamos, é inequivocadamente à esquerda, numa recusa da ortodoxia. A dúvida hoje é saber quem está do nosso lado, e quem forma o campo progressista.

\section{Referências}

BARR, Nicholas. The Economics of the Welfare State. Oxford: Oxford University Press, 2004. CHANT, Sylvia. Gender, Generation and Poverty. Northampton, USA: Edward Elgar, 2007.

COBO, Barbara. Políticas Focalizadas de Transferência de Renda. Contextos e Desafios. São Paulo: Cortez Editora, 2012.

LAVINAS, Lena. "A Financeirização da Política Social: o caso brasileiro". Politika, n. 2, jul. 2015. Rio de Janeiro: Fundação João Mangabeira em colaboração com HumboldtViadrina Governance Platform, 2015, p. 35-51.

"Notas sobre os desafios da redistribuição no Brasil". FONSECA, Ana e FAGNANI, Eduardo

(Orgs.). Políticas Sociais, Desenvolvimento e Cidadania. São Paulo: Fundação Perseu Abramo, tomo 1, 2013a, p. 99-143. . "21 st Century Welfare". New Left Review 84, p. 5-40, $2013 \mathrm{~b}$.

"Transferências de Renda: o quase tudo do sistema de proteção social brasileiro". In.: SICSÚ, João (Org.). Arrecadação, de onde vem? Gastos Públicos, para onde vão? São Paulo: Boitempo Editorial, 2007, p. 51-68.

LAVINAS, Lena; COBO, Barbara; VEIGA, Alinne. "Bolsa-família: impacto das transferências de renda sobre a autonomia das mulheres e as relações de gênero". Revista Latinoamericana de Población, RELAP, Asociación Latinoamericana de Población, año 6, n. 10, p. 31-54, enero/junio 2012.

LO VUOLO, Rubén. "The Limits of Redistributive Policies in Latin America: complementarities between economic and social protection systems". FRITZ, Barbara; LAVINAS, Lena. A Moment of Equality of Latin America? Challenges for Redistribution. Burlington: Ashgate, 2015, p. 31-51.

\footnotetext{
${ }^{4} \mathrm{O}$ documento está equivocado ao afirmar à página 211 que o Brasil instituiu o IOF para financiar políticas sociais, na área da saúde e da assistência, citando expressamente o Bolsa Família. Isso não procede. Da mesma maneira, aponta acertadamente ter o Banco Central baixado a taxa de juros no início de 2009, em reação aos rebatimentos da crise internacional (UN WOMEN, 2015, p. 215). Mas omite que tal movimento foi interrompido precipitadamente com a elevação das taxas de juros a partir de 2012 e o recuo do investimento público. Logo, deixa supor que o Brasil adotou um padrão monetário expansivo, quando isso não aconteceu, causa, segundo muitos economistas, da rápida perda de dinamismo da economia brasileira. Finalmente coloca num mesmo saco Brasil, China e Chile, entre outras referências, como países que adotaram mecanismos de controle de capitais, quando tais políticas - se à entrada ou à saída - variaram muito, com efeitos radicalmente distintos no que tange a entrada massiva de capitais especulativos e para investimento (UN WOMEN, 2015, p. 217). Tal imprecisão induz confusão no entendimento do leitor.
} 
"Introduction". LO VUOLO, Rubén (Ed.). Citizen's Income and Welfare Regimes in Latin America. From Cash Transfers to Rights. New York: Palgrave MacMillan, 2013, p. 1-26. MOLYNEUX, Maxime. "Mothers at the Service of the New Poverty Agenda: Progresa/ Oportunidades, Mexico's Conditional Transfer Programme". Social Policy \& Administration, v. 40 , n. 4, p. 420-449, august 2006.

THERBORN, Göran. The Killing Fields of Inequality. Cambridge: Polity Press, 2013.

UN WOMEN. Progress of the World's Women 2015-2016. Transforming Economies, Realizing

Rights. New York: United Nations, 2015. Available from: <http://progress.unwomen.org/ en/2015/pdf/UNW_progressreport.pdf $>$. Access on 02/02/2016.

[Dossiê proposto em 6/07/2015

apresentado em 12/01/2016

aceito para publicação em 29/02/2016]

It's the Macroeconomy, Stupid!

Abstract: This articles aims at discussing some concerns addressed by the recent UN Report named Progress on the World's Women 2015-2016 - Transforming Economies, Realizing Rights. The UN Report rightly draws attention to the persistence of gender asymmetries in our contemporary world. Moreover, it examines how orthodox macroeconomic policies reinforce gender inequalities by promoting cutbacks in public spending as well as by narrowing the scope of universal policies. Keywords: UN Women; gender and macroeconomics; gender and heterodox policies. 